\title{
Synthesis, Characterization and Biological Evaluation of Some Novel Benzimidazole Derivatives
}

\author{
Marthe C. D. Fotsing, and Derek T. Ndinteh
}

\begin{abstract}
The synthesis of a series of propynamide benzimidazolines derivatives by Michael addition of amino benzimidazoles on allenic acids in ethanol under reflux conditions is reported. The compounds were isolated in good yields and fully characterized by spectral and microanalytical data. Excellent antibacterial activity was recorded with values ranging from 62.5 $\mu \mathrm{g} / \mathrm{mL}$ to $500 \mu \mathrm{g} / \mathrm{mL}$.
\end{abstract}

Keywords - Benzimidazole, Michael addition, biological activity

\section{INTRODUCTION}

The therapeutic journey of benzimidazoles started in 1944 when Woolley speculated that they simulate purines biological behavior [1]. Over the years of systematic research, the benzimidazole unit has emerged as an important heterocyclic unit because of its widespread occurrence in bioactive compounds like antiparasitic, antiulcer, antiviral and anti-inflammatory agents [2]-[4]. Benzimidazoles can be identified as a "Master Key" because they are part of the core structure of many biological active compounds such as vitamin-B12, etc. They have been reported in literature to possess antihypertensive [5]-[6], anti-inflammatory [7]-[9], anti-oxidant [10]-[11], antitumor [12]-[13], and antidiabetic [14] properties. The report of Iwahi and Satoh in the year 2000 on the antibacterial activities of 2-(substituted pyridyl methylsulfinyl)benzimidazole against Campylobacter pylori prompted many research activities on their antimicrobial potential [15]. This yielded several compounds whose activity was better than some commercially available antibiotics. Attachment of some other heterocycles to the benzimidazole nucleus resulted in compounds with interesting antifungal and antibacterial activities [16]-[20]. Some benzimidazoles derivatives have also been found to have excellent activities against, methicillin resistant Staphylococcus aureus (MRSA) and methicillin resistant Staphylococcus epidermis (MRSE) [21], [22]. With the rise of antimicrobial resistance worldwide,

Manuscript received on June 13, 2017. The authors are grateful to the National Research Foundation (NRF) for financial support to Dr. M. C. D. Fotsing (through grant number 99704). This work was also supported by the 2015 AGNES grant to junior researchers and the University of Johannesburg.

M. C. D. Fotsing is a postdoctoral research fellow in the Department of Applied Chemistry at the University of Johannesburg. (E-mail: carinemarthe@gmail.com).

Derek Tantoh Ndinteh is a senior lecturer in the department of Applied Chemistry at the University of Johannesburg (E-mail: dndinteh@uj.ac.za). there is an urgent need to produce more effective therapeutic alternatives [23].

\section{General Procedures}

\section{A. Materials and Methods}

Unless otherwise specified, the starting materials were commercially available. Solvents were purified by conventional methods before use. Infra red (IR) spectra were recorded using a Perkin Elmer (spectrum 100) FT-IR SPECTROMETER. ${ }^{1} \mathrm{H}$ NMR (300 MHz), and ${ }^{13} \mathrm{C}$ NMR (75 MHz) were measured on a Mercury-300 broadband "univn200" NMR spectrometer. Chemical shifts are reported in parts per million (ppm, $\delta$ ), downfield from residual solvents peaks and coupling constants are reported as Hertz $(\mathrm{Hz})$. Splitting patterns are designated as singlet (s), doublet (d), triplet ( $\mathrm{t})$... Splitting patterns that could not be interpreted or easily visualized are designated as multiplet $(\mathrm{m})$. The bacterial strains were obtained from Davies diagnostics.

\section{B. Bacteria}

Fourteen bacterial strains (Gram-positive bacteria: Bacillus cereus (ATCC10876), B. subtilis (ATCC19659), Enterococcus faecalis (ATCC13047), Mycobacterium smegmatis $\left(\mathrm{MC}^{2} 155\right.$, kind gift from the Centre of Excellence in Biomedical TB Research, University of the Witwatersrand), Staphylococcus epidermidis (ATCC14990) and S. aureus (ATCC25923). Gram-negative bacteria: Enterobacter cloacae (ATCC13047), Escherischia coli (ATCC25922), Klebsiella oxytoca (ATCC8724), K. pneumonia (ATCC13882), Proteus mirabilis (ATCC7002), Pseudomonas aeruginosa (ATCC27853), Enterobacter aerogenes(ATCC13048) and Proteus vulgaris(ATCC6380) were cultured overnight in Mueller-Hinton broth at $25{ }^{\circ} \mathrm{C}$; Merck Chemicals, SA). The turbidity of the culture solutions was adjusted to match a 0.5 McFarland standard within 15 minutes prior to antibacterial testing.

\section{Antibacterial Testing}

Minimum inhibitory concentrations (MIC) of all the strains were determined by the broth microdilution assay described in literature [24] . The test compounds were accurately weighed and dissolved in DMSO to yield $1000 \mu \mathrm{g} / \mathrm{ml}$. The dissolved compounds were then serially diluted in Mueller-Hinton broth till the lowest concentration of $15.62 \mu \mathrm{g} / \mathrm{ml}$. All dilutions were tested two-fold against each bacterial strain. $100 \mu 1$ of the 
bacterial suspension was mixed with $100 \mu$ l of pre-diluted test compound in a 96 microwell plate and left to incubate overnight at $37{ }^{\circ} \mathrm{C}$. $10 \mu \mathrm{l}$ of a $0.02 \%(\mathrm{w} / \mathrm{v})$ tetrazolium sodium solution was added to each well and the plates were re-incubated for 2 hours. Visual change of the solution from blue to pink indicated that the bacteria were still alive. MIC was determined as the minimum concentration of compound where no color change could be observed. The MIC of all strains tested were compared to two reference antibiotics (nalidixic acid and streptomycin sulphate). This was due to the fact that whilst streptomycin is a broad based antibiotic, nalidixic acid has been shown to be exclusively active against Gram-negative bacteria [25].

D. Synthesis of Synthesis of prop-2-ynamideiminobenzimidazoles derivatives

Preparation of propynamide benzimidazolines derivatives: Phenyl or n-pentylpropyne acetylenic acids were heated under reflux with 2-aminobenzimidazoles or 5,

6-dimethyl-2-aminobenzimidazoles in ethanol overnight. A solid was recovered after solvent evaporation.

5a: $N$-(1,3-dihydrobenzimidazol-2-ylidene)-3-phenylprop-2-ynamide

Yield $80 \%$, amorphous powder, ${ }^{1}$ H NMR (DMSO, 300 MHz) $\delta(\mathrm{ppm}) 7.11(\mathrm{~m}, 1 \mathrm{H}) ; 7.28(\mathrm{~m}, 2 \mathrm{H}), 7.39\left(\mathrm{~d}, 2 \mathrm{H},{ }^{3} \mathrm{~J}_{\mathrm{HH}}\right.$ =6.8); 7.47(m, 4H), 8.27(s, 2NH $).{ }^{13} \mathrm{C}$ NMR (DMSO, 75 MHz) $\delta$ (ppm): 72.30; 83.00;116.96; 117.62; 122.93; 123.97; $124.33 ; 129.00 ; 129.32 ; 129.65 ; 143.26 ; 143.62 ; 143.97$, 147.46; 154.77. IR (film, $\mathbf{c m}^{-1}$ ): 3228; 2999; 2879, 2765, $2663 ; 2017 ; 2883 ; 2772 ; 2202 ; 1736 ; 1684 ; 1613 ; 1557 ; 1360$; $1272 ; 1208 ; 1033 ; 929 ; 889 ; 826 ; 749 ; 674 .[\mathrm{M}+\mathrm{H}]^{+}: \mathrm{m} / \mathrm{z} 262$.

5b: $N$-(5,6-dimethyl-1,3-dihydrobenzimidazol-2-ylidene)-3phenyl-prop-2-ynamide

Yield $85 \%$, amorphous powder, ${ }^{1}$ H NMR (DMSO, 300 MHz) $\delta$ (ppm): 4.98(s, 2H), $5.72(\mathrm{~m}, 3 \mathrm{H}), 5.80(\mathrm{~m}, 2 \mathrm{H})$. ${ }^{13}$ NMR (DMSO, 75 MHz) $\delta$ (ppm): 15.08; 73.83; 84.58; $118.80 ; 119.12 ; 124.41 ; 125.20 ; 126.45 ; 127.81 ; 130.50$; $131.16 ; 144.74 ; 145.10 ; 145.46 ; 148.83 ; 156.34$. IR (film, $\left.\mathbf{c m}^{-1}\right): 3456 ; 2957 ; 246 ; 2200 ; 139 ; 1673 ; 1576 ; 1366 ; 1217$; $1012 ; 960 ; 811 ; 742 .[\mathrm{M}+\mathrm{H}]^{+}: \mathrm{m} / \mathrm{z} 290$

5c: $N$-(1,3-dihydrobenzimidazol-2-ylidene)oct-2-ynamide Yield $82 \%$, amorphous powder, ${ }^{1}$ H NMR (DMSO, 300 MHz) $\delta(\mathrm{ppm}): 0.81\left(\mathrm{t}, 2 \mathrm{H},{ }^{3} J_{\mathrm{HH}}=7.20\right) ; 1.15(\mathrm{~m}, 4 \mathrm{H}), 1.30(\mathrm{~m}$, $2 \mathrm{H}) ; 2.21\left(\mathrm{t}, 2 \mathrm{H},{ }^{3} J_{\mathrm{HH}}=1.9\right) ; 2.30(\mathrm{~s}, 2 \mathrm{H}) 715(\mathrm{~m}, 2 \mathrm{H}) ; 7.25(\mathrm{~m}$, 2H); 7.39(m, 1H). ${ }^{13}$ C NMR (DMSO, 75 MHz) $\delta(\mathrm{ppm})$ : $12.30 ; 16.00 ; 22.00 ; 25.69 ; 75.60 ; 85.95 ; 116.98 ; 117.31$; $129.03 ; 129.69 ; 143.23 ; 143.59 ; 143.95 ; 148.00 ; 155.20$. IR (film, cm$^{-1}$ ): 3458; 2970; 2948; 2238; 2208; 1740; 1680; 1609; $1555 ; 1488 ; 1441 ; 1365 ; 1216 ; 1093 ; 1025 ; 838 ; 775 ; 687$. $[\mathrm{M}+\mathrm{H}]^{+}: \mathrm{m} / \mathrm{z} 256$

5d: N-(5,6-dimethyl-1,3-dihydrobenzimidazol-2-ylidene) oct-2-ynamide

Yield $88 \%$, amorphous powder, ${ }^{1}$ H NMR (DMSO, 300 MHz) $\delta(\mathrm{ppm}): 0.859\left(\mathrm{t}, 2 \mathrm{H},{ }^{3} \mathrm{~J}_{\mathrm{HH}}=6.3\right) ; 1.29(\mathrm{~m}, 4 \mathrm{H}), 1.43(\mathrm{~m}$, $2 \mathrm{H}) ; 2.50\left(\mathrm{t}, 2 \mathrm{H},{ }^{3} \mathrm{~J}_{\mathrm{HH}}=1.8\right) ; 7.04(\mathrm{~s}, 2 \mathrm{H}) ; 8.34(\mathrm{~s}, 2 \mathrm{H}) .{ }^{13} \mathbf{C ~ N M R}$ (DMSO, 75 MHz) $\delta$ (ppm): 14.50; 18.36; 20.30; 22.30; 28.17;
$31.12 ; 80.22 ; 80.69 ; 112.38 ; 129.97 ; 130.88 ; 152.68 ; 159.57$. IR (film, $\mathbf{~ c m}^{-1}$ ): 3452; 3023; 2969; 2920; 2717; 2232; 1738; $1679 ; 1606 ; 1554 ; 1481 ; 1439 ; 1366 ; 1217 ; 1030 ; 845 ; 777$; 689. $[\mathrm{M}+\mathrm{H}]^{+}: \mathrm{m} / \mathrm{z} 284$.

\section{RESULTS AND DISCUSSION}

The conjugate addition of 2-aminobenzimidazole $\mathbf{1}$ to acetylenic acids $\mathbf{2}$ followed by a prototropic rearrangement yielded the corresponding (3-pentyl)-prop-2-ynamideiminobenzimidazoles 5a-5b and (3-phenyl)-prop-2-ynamideiminobenzimidazoles 5c-5d in good yields (Scheme 1).
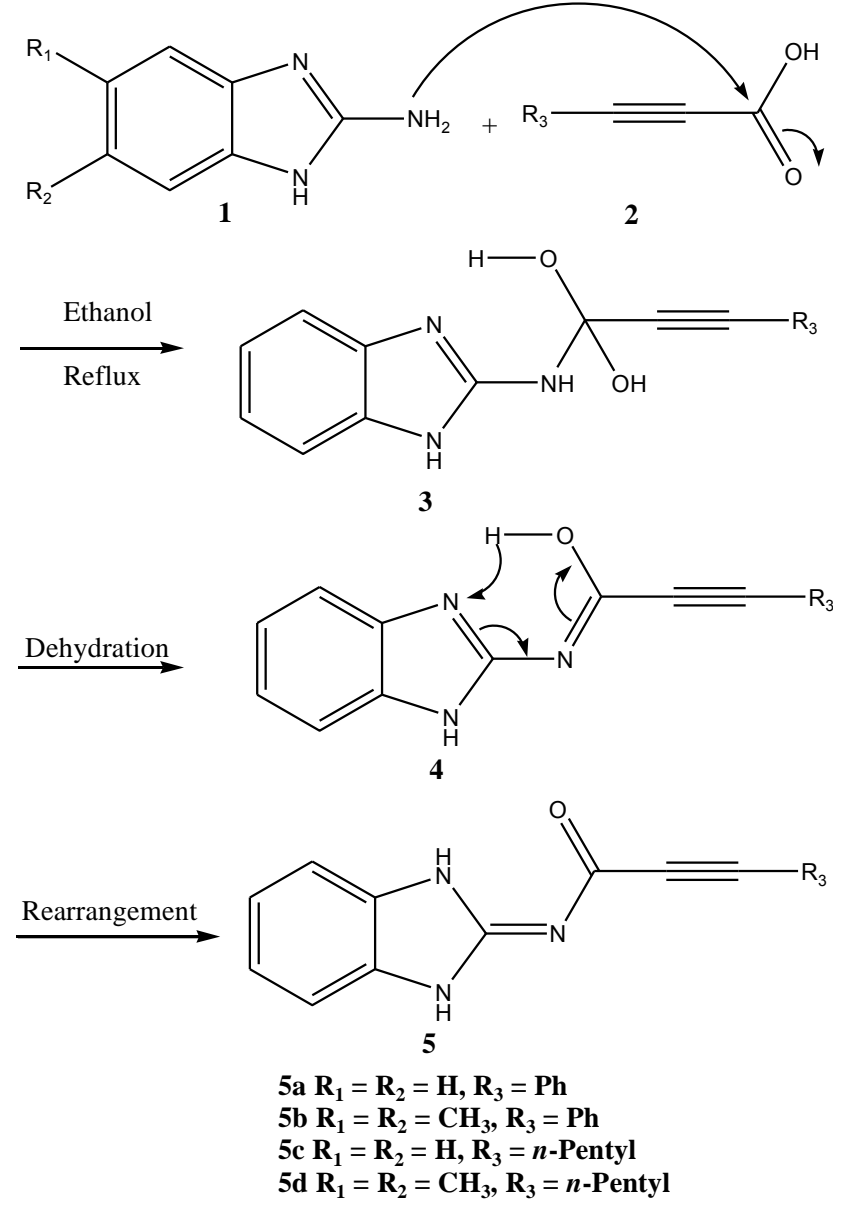

Scheme 1: Synthesis of prop-2-ynamide- iminobenzimidazoles deriva tives

The reaction of $\mathbf{2}$ and 2-aminobenzimidazole proceeds by the initial attack of the 2-amino group on the carbon $\mathrm{C}-3$. The IR, ${ }^{1} \mathrm{H}-\mathrm{NMR},{ }^{13} \mathrm{C}-\mathrm{NMR}$ and the mass spectral data of the products are consistent with the structures assigned to $\mathbf{5 a - 5 d}$. The carbon-carbon triple bond stretch appears around $2200 \mathrm{~cm}^{-1}$. A strong carbonyl stretching is seen around 1736 $\mathrm{cm}^{-1}$ and the imine stretch just follows at $1680 \mathrm{~cm}^{-1}$. In the proton NMR spectra of compounds 5 and $\mathbf{5 b}$, the aromatic protons appear at their expected position in the downfield region. For compounds $\mathbf{5} \mathbf{c}$ and $\mathbf{5 d}$, the aliphatic protons appear in the upfield region. In the ${ }^{13} \mathrm{C}$ NMR spectrum of all the compounds, the carbonyl carbon and the imine carbon appear in the downfield region respectively around $\delta 159$ and $152 \mathrm{ppm}$. The carbon triple bond signals are between $\delta 70$ and 80 ppm. 
The aromatic carbons appear in the downfield region as expected.

There is no indication of an initial attack from the internal amino group as suggested in Scheme $\mathbf{2}$ as no pyrimido benzimidazoles ketones $\mathbf{8}$ were recovered.

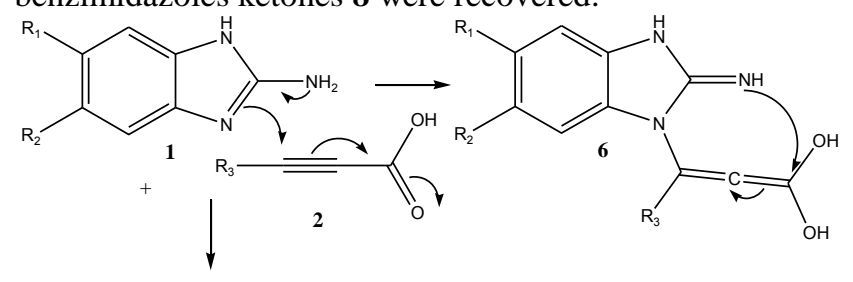<smiles>[R]C1=CC(O)(O)N=C2Nc3cc([R])c([R9])cc3N12</smiles>

All the synthesized compounds were tested against 14 strains of bacteria. Table 1 summarizes the results for compounds 5a-5d against the tested bacteria. All the compounds showed an activity against all the strains.

All the compounds showed better activity than Nalidixic acid against Enterococcus faecalis, Escherichia coli, Mycobacterium smegmatis,Pseudomonas aeruginosa and Staphylococcus aureus. We also recorded a MIC of $250 \mu \mathrm{g} / \mathrm{ml}$ against Enterococcus cloacae which is much better than that of Streptomycin.

The best activity was showed by compound $\mathbf{5 b}$ against Mycobacterium smegmatis, which performed better than nalidixic acid with a MIC of $62.5 \mu \mathrm{g} / \mathrm{ml}$.

Scheme 2: An alternative mechanistic pathway

TABLE I: MIC OF PROP-2-YNONE- IMINOBENZIMIDAZOLES DERIVATIVES ((MG/ML))

\begin{tabular}{|c|c|c|c|c|c|c|}
\hline Bacterial strain & $5 \mathrm{a}$ & $5 b$ & $5 \mathrm{c}$ & $5 d$ & Streptomycin & Nalidixic acid \\
\hline Bacillus cereus & 500 & 500 & 250 & 250 & 32 & 32 \\
\hline Bacillus subtilis & 125 & 250 & 250 & 125 & 16 & 16 \\
\hline Enterococcus faecalis & 500 & 250 & 250 & 250 & 128 & $>512$ \\
\hline Enterobacter cloacae & 250 & 250 & 250 & 250 & $>512$ & 16 \\
\hline Enterobacter aerogenes & 500 & 500 & 500 & 250 & 16 & 256 \\
\hline Escherichia coli & 500 & 250 & 250 & 250 & 64 & $>512$ \\
\hline Klebsiella oxytoca & 250 & 250 & 250 & 250 & 16 & 8 \\
\hline Klebsiella pneumoniae & 500 & 125 & 500 & 250 & 64 & 64 \\
\hline Mycobacterium smegmatis & 125 & 62.5 & 125 & 250 & $<4$ & $>512$ \\
\hline Pseudomonas aeruginosa & 250 & 250 & 250 & 250 & 64 & $>512$ \\
\hline Proteus mirabilis & 500 & 500 & 500 & 500 & 128 & 32 \\
\hline Proteus vulgaris & 500 & 250 & 250 & 500 & 32 & 8 \\
\hline Staphylococcus aureus & 500 & 250 & 250 & 250 & 64 & 512 \\
\hline Staphylococcus epidermidis & 250 & 250 & 500 & $>500$ & 8 & 64 \\
\hline
\end{tabular}

\section{CONCLUSION}

In conclusion, we have reported the synthesis of 4 novel heterocycles in good yields via the Michael addition of 2-aminobenzimidazoles on acetylenic acids. These compounds have been fully characterized by various spectroscopic methods. They have also been tested for biological activity and were tested against 14 strains of bacteria. $N$-(5,6-dimethyl-1,3-dihydrobenzimidazol-2-ylidene)-3-phenyl -prop-2-ynamide 5b, showed very good activity against Mycobacterium smegmatis compared to Nalidixic acid.

\section{REFERENCES}

[1] D. W. Woolley, "Some biological effects produced by benzimidazole and their reversal by purines," J. Biol. Chem., vol. 152, pp. 225-232, 1944.
[2] A. Patil, S. Ganguly, and S. Surana, "A systematic review of benzimidazole derivatives as an antiulcer agent," Rasayan J. Chem., vol. 1, no. 3, pp. 447-460, 2008.

[3] M. Boiani and M. Gonzalez, "Imidazole and Benzimidazole Derivatives as Chemotherapeutic Agents," Mini-Reviews Med. Chem., vol. 5, no. 4, pp. 409-424, 2005.

[4] Y. Bansal and O. Silakari, "The therapeutic journey of benzimidazoles: A review," Bioorg. Med. Chem., vol. 20, no. 21, pp. 6208-6236, 2012.

[5] M. S. Sharma, R. Singh, S. S. Kale, D. Agrawal, B. S. Sharma, and A. K. Mahapatra, "Tumor control and hearing preservation after Gamma Knife radiosurgery for vestibular schwannomas in neurofibromatosis type 2 ," $J$. Neurooncol., vol. 95, no. 2, pp. 265-270, 2010.

[6] S. Estrada-Soto et al., "Relaxant activity of 2-(substituted phenyl)-1H-benzimidazoles on isolated rat aortic rings: Design and synthesis of 5-nitro derivatives," Life Sci., vol. 79, no. 5, pp. 430-435, 2006.

[7] K. C. S. Achar, K. M. Hosamani, and H. R. Seetharamareddy, "In-vivo analgesic and anti-inflammatory activities of newly synthesized 
benzimidazole derivatives.," Eur. J. Med. Chem., vol. 45, no. 5, pp. 2048-54, May 2010.

[8] M. Gaba, D. Singh, S. Singh, V. Sharma, and P. Gaba, "Synthesis and pharmacological evaluation of novel 5-substituted-1-(phenylsulfonyl)-2-methylbenzimidazole derivatives as anti-inflammatory and analgesic agents.," Eur. J. Med. Chem., vol. 45, no. 6, pp. 2245-9, Jun. 2010.

[9] M. Sabat et al., "The development of 2-benzimidazole substituted pyrimidine based inhibitors of lymphocyte specific kinase (Lck).," Bioorg. Med. Chem. Lett., vol. 16, no. 23, pp. 5973-7, Dec. 2006.

[10] C. Kuş et al., "Synthesis and antioxidant properties of novel $\mathrm{N}$-methyl-1,3,4-thiadiazol-2-amine

and 4-methyl-2H-1,2,4-triazole-3(4H)-thione derivatives of benzimidazole class.," Bioorg. Med. Chem., vol. 16, no. 8, pp. 4294-303, Apr. 2008.

[11] E. R. Cole, G. Crank, and A. Salam-Sheikh, "Antioxidant properties of benzimidazoles," J. Agric. Food Chem., vol. 22, no. 5, pp. 918-918, 1974.

[12] M. Hranjec, G. Pavlović, M. Marjanović, M. Kralj, and G. Karminski-Zamola, "Benzimidazole derivatives related to 2,3-acrylonitriles, benzimidazo[1,2-a]quinolines and fluorenes: synthesis, antitumor evaluation in vitro and crystal structure determination.," Eur. J. Med. Chem., vol. 45, no. 6, pp. 2405-17, Jun. 2010.

[13] H. M. Refaat, "Synthesis and anticancer activity of some novel 2-substituted benzimidazole derivatives.," Eur. J. Med. Chem., vol. 45, no. 7, pp. 2949-56, Jul. 2010.

[14] M. Ishikawa et al., "Discovery of novel 2-(pyridine-2-yl)-1H-benzimidazole derivatives as potent glucokinase activators.," Bioorg. Med. Chem. Lett., vol. 19, no. 15, pp. 4450-4, Aug. 2009.

[15] T. Iwahi and H. Satoh, "Patent 5013," 1991.

[16] B. V. S. Kumar, S. D. Vaidya, R. V. Kumar, S. B. Bhirud, and R. B. Mane, "Synthesis and anti-bacterial activity of some novel 2-(6-fluorochroman-2-yl)-1-alkyl/acyl/aroyl-1H-benzimidazoles.," Eur. J. Med. Chem., vol. 41, no. 5, pp. 599-604, May 2006.

[17] K. F. Ansari and C. Lal, "Synthesis and biological activity of some heterocyclic compounds containing benzimidazole and beta-lactam moiety," J. Chem. Sci., vol. 121, no. 6, pp. 1017-1025, 2009.

[18] K. F. Ansari and C. Lal, "Synthesis and evaluation of some new benzimidazole derivatives as potential antimicrobial agents," Eur. J. Med. Chem., vol. 44, no. 5, pp. 2294-2299, 2009.

[19] K. F. Ansari and C. Lal, "Synthesis, physicochemical properties and antimicrobial activity of some new benzimidazole derivatives," Eur. J. Med. Chem., vol. 44, no. 10, pp. 4028-4033, 2009.

[20] C. Gill et al., "Clubbed [1,2,3] triazoles by fluorine benzimidazole: A novel approach to H37Rv inhibitors as a potential treatment for tuberculosis," Bioorg. Med. Chem. Lett., vol. 18, no. 23, pp. 6244-6247, 2008.

[21] R. W. Huigens et al., "The chemical synthesis and antibiotic activity of a diverse library of 2-aminobenzimidazole small molecules against MRSA and multidrug-resistant A. baumannii," Bioorganic Med. Chem., vol. 18, no. 2, pp. 663-674, 2010.

[22] H. Göker, D. W. Boykin, and S. Yildiz, "Synthesis and potent antimicrobial activity of some novel 2-phenyl or methyl-4H-1-benzopyran-4-ones carrying amidinobenzimidazoles.," Bioorg. Med. Chem., vol. 13, no. 5, pp. 1707-14, 2005.

[23] D. I. Andersson and D. Hughes, "Persistence of antibiotic resistance in bacterial populations," FEMS Microbiol. Rev., vol. 35, no. 5, pp. 901-911, 2011.

[24] J. Andrews, "Determination of minimum inhibitory concentrations.," $J$. Antimicrob. Chemother., vol. 48, pp. 5-16, 2001.

[25] A. Dalhoff, "In vitro activities of quinolones.," Expert Opin. Investig. Drugs, vol. 8, pp. 123-137, 1999. 